\title{
Evidence of increased non-verbal behavioral signs of pain in adults with neurodevelopmental disorders and chronic self- injury
}

\author{
Frank J. Symons ${ }^{1}$, Vicki N. Harper ${ }^{4}$, Patrick J. McGrath ${ }^{3}$, Lynn M. Breau ${ }^{3}$, and James W. \\ Bodfish $^{2,4}$ \\ ${ }^{1}$ University of Minnesota \\ 2University of North Carolina at Chapel Hill \\ ${ }^{3}$ Dalhousie University \\ ${ }^{4}$ J.Iverson Riddle Developmental Center
}

\section{Abstract}

The role of pain in relation to self-injurious behavior (SIB) among individuals with intellectual disabilities is not well understood. Some models of SIB are based on altered endogenous opioid system activity which could result in elevated pain thresholds. In this study, non-verbal behavioral signs indicative of pain as measured by the Non-Communicating Children's Pain Checklist (NCCPC) were compared between matched individuals with $(\mathrm{N}=35)$ and without $(\mathrm{N}=35)$ chronic self-injurious behavior (SIB) and neurodevelopmental disorders. Significant $(p<0.01)$ between group differences (SIB Group > Control Group) were found for the NCCPC Total Score, and for the Vocal, Social/Personality, and Eating/Sleeping subscales of the NCCPC. These results are not consistent with models of SIB in which pain sensitivity is assumed to be attenuated because of opioid system activity and are suggestive of intact and possibly amplified pain expression.

Self-injurious behavior (SIB) is among the most damaging and destructive behavior disorders among individuals with intellectual and developmental disabilities. Significant gains have been made in the past decade in the area of effective behavioral and pharmacological treatments for many individuals with SIB (Schroeder, et al., 2001). For other individuals, however, chronic self-injury occurring at high rates over long time periods can result in irreversible tissue damage, sensory-impairment, or brain injury.

A long standing but untested clinical impression about individuals with intellectual disabilities who self-injure is that they are insensitive to pain and/or the perception of pain is diminished (Stengel, Oldham, \& Ehrenberg, 1955; Rojahn, Schroeder, \& Hoch, 2008). The assumption is based, in part, on the observation that some individuals engage in forms of destructive behavior severe enough to cause permanent scarring and disfigurement. If pain were intact, so the argument goes, it would function to suppress extreme forms of self-

\footnotetext{
(C) 2008 Elsevier Ltd. All rights reserved.

Correspondence to: Frank Symons, Department of Educational Psychology, Education Sciences Building 56 River Road, University of Minnesota, Minneapolis, MN 55455, (t) 612.626.8697, (e) symon007@umn.edu..

Publisher's Disclaimer: This is a PDF file of an unedited manuscript that has been accepted for publication. As a service to our customers we are providing this early version of the manuscript. The manuscript will undergo copyediting, typesetting, and review of the resulting proof before it is published in its final citable form. Please note that during the production process errors may be discovered which could affect the content, and all legal disclaimers that apply to the journal pertain.
} 
injury. Therefore, extremely damaging forms of self-injury are taken as confirmatory evidence that pain sensitivity is reduced or absent. Scientifically, the opioid model of selfinjury (Sandman, 1988) is most directly related to the issue of pain sensitivity. In this model, opioid receptors are congenitally upregulated which could result in elevated pain thresholds and, theoretically, this would be consistent with the clinical impressions (noted above) of apparent reduced sensitivity to pain in many individuals exhibiting SIB.

The role of pain in relation to self-injury is not well understood, however (Barrera, Toedoro, Selmeci, \& Madappuli, 1994; Sandman, 1988; Sandman, Spence, \& Smith, 1999; Symons, 2002). The definition of pain (i.e., an unpleasant sensory and emotional experience associated with actual or potential tissue damage, or described in terms of such damage) includes both emotional and sensory components that can be difficult to assess in individuals with intellectual and developmental disabilities who are nonverbal and/or otherwise language and cognitively impaired (Bieserdorff, 1991; 1994). Because of this, our current knowledge base concerning pain in intellectual and developmental disabilities in general and in relation to self-injury is limited.

In other nonverbal, preverbal, or communicatively limited populations (e.g. neonates, infants, children, adults with dementia) objective measurement strategies have emerged and been used to identify pain based on empirically validated pain scales and coding of expression during known painful events such as vaccination, blood draw, or other invasive procedures (Breau, McGrath, Camfield, Rosmus, \& Finley, 2000; Grunau \& Craig, 1987; 1990; Howard, 2003; Oberlander, Gilbert, Chambers, O’Donnell, \& Craig, 1999). This work draws upon the large base of empirical evidence for objective, nonverbal signs of emotional expression in humans (Izard, Huebner, Risser, McGinnes, \& Dougherty, 1980).

In studies of individuals with intellectual and developmental disabilities, a body of work is emerging with the purpose of identifying non-verbal pain related behaviors associated with acute and chronic pain episodes (Breau, Camfield, McGrath, \& Finley, 2003; Defrin, Pick, Peretz, \& Carmeli, 2004; LaChapelle, Hadjistavropoulos, \& Craig 1999; McGrath, Rosmus, Camfield, Campbell, \& Hennigar, 1998). Collectively, results show that pain behaviors among nonverbal individuals with intellectual and developmental disabilities correspond to the timing of the putative painful event (although not always, see Oberlander et al., 1999). Importantly, the studies demonstrate that the magnitude of pain expression in nonverbal persons with severe cognitive disabilities can be reliably quantified. These studies of the objective measurement of pain expression in persons with severe intellectual impairment have consistently shown that painful events reliably occasion the forms of nonverbal pain expression seen in persons without developmental disabilities. To date, such objective techniques for measuring pain expression have not been applied to adult individuals with chronic SIB.

In the first study of its kind, Breau, Camfield, Symons, et al. (2003) used a validated pain scale and compared children with severe cognitive impairments and associated communicative difficulties with and without self-injury. Findings suggested that children with severe cognitive impairments and SIB did not appear to have reduced pain expression and that chronic pain may influence the frequency and location of SIB. No study has examined the nonverbal behaviors associated with pain expression in adults with developmental disabilities and chronic SIB. The purpose of this preliminary study was to examine differences in nonverbal behaviors associated with pain and discomfort between adult individuals with intellectual disabilities with and without self-injurious behavior. 


\section{Method}

\section{Participants}

Seventy adults with intellectual and developmental disabilities participated in this study (SIB Group $n=35$, No SIB Control Group $n=35$ ). Control participants were matched on chronological age (within a 5 year period), level of mental retardation (exact match based on DSM-IV levels - mild, moderate, severe, or profound level of mental retardation), gender (exact match), and use of psychotropic medication (i.e. medication prescribed for behavioral or emotional disorders). The mean age for each group was 37.8 years (range 29-51 years) for the SIB Group and 35.6 years (range 23-48 years) for the Control Group. Males comprised $57 \%$ of both groups; $8.6 \%$ of the sample functioned in the moderate range of mental retardation, $8.6 \%$ of the sample functioned in the severe range of mental retardation, and $82.8 \%$ of the sample functioned in the profound range of mental retardation. Thirtyseven percent of the sample was prescribed psychotropic medication. Chi-square tests showed no significant differences in the demographic (age, IQ, gender) or clinical (treatment with psychotropic medication) characteristics of SIB and non-SIB groups. Participants resided in a residential facility providing services for individuals with complex behavioral and/or medical needs.

\section{Inclusion/Exclusion criteria}

SIB participants were selected based on the following criteria (a) presence of self-injurious behavior that occurred at least weekly (as determined by the SIB subscale of the Behavior Problem Inventory (Rojahn, Matson, Lott, Esbensen, \& Smalls, 2001), (b) tissue damaging self-injury (presence of bruise, wound, or scarring related to SIB as determined by examination using the Self-Injury Trauma Scale (Iwata, Pace, Kissel, Nau, \& Farber 1990) (c) chronic (i.e., exhibited for at least 12 consecutive months), and (d) treatment refractory (SIB continued to require formal behavioral and or medical/psychiatric intervention due to rate or potential for injury). Non SIB Control participants were identified by medical chart review (i.e. did not have SIB documented as a focus of treatment) and was confirmed by the Behavior Problem Inventory (SIB Subscale). Individuals with known acute medical conditions thought to be painful (e.g., musculoskeletal disorders, spasticity associated with cerebral palsy, esophageal reflux) were excluded from both groups. Primary care staff respondents were selected based on working directly with participants (on a daily basis) and therefore having a reasonable knowledge of the participant for a minimum of six months.

\section{Measures}

Primary care staff completed an adapted 'Non-Communicating Children's Pain Checklist (NCCPC, Breau, et al., 2001; McGrath, et al. 1998). The scale is an observational pain measure consisting of seven domains including Vocal, Eating/Sleeping, Social/Personality, Facial Expression, Activity, Body/Limbs, and Physiological (minor item adaptations in wording were made to accommodate an adult vs. pediatric sample). Items are endorsed using as present/absent and intensity rated through a 4-point behavioral rating scale format. The NCCPC has been validated with children with cognitive and communicative impairments and was developed initially through primary caregiver and professional item endorsement (McGrath, et al. 1998) followed by direct observation validation studies (Breau, McGrath, Camfield, Rosmus, \& Finley, 2000). The NCCPC has shown validity and reliability for everyday pain among children with developmental disabilities (Breau, McGrath, Camfield, \& Finley, 2002) and a post-operative version has excellent psychometric properties for use following surgical interventions (Breau, Finley, McGrath, \& Camfield, 2002). Since the time of this study's initial data collection, the NCCPC was revised (NCCPC-R) and has been applied to study the relation between pain and self-injury in non-verbal children with severe intellectual impairments (Breau, Camfield, Symons, et al. 
2003), the incidence of pain in children with severe intellectual impairments (Breau, et al., 2003), and the effects of pain on adaptive behavior in children with intellectual impairments (Breau, Camfield, McGrath, \& Finley, 2007).

\section{Procedures}

The NCCPC was completed by direct care staff to determine how frequently individuals typically showed each pain-related behavior in the past week: not at all (0), just a little (1), fairly often (2), and very often (3). Seven days (i.e., one week) was selected for recall because studies of this type have used this time interval previously among pediatric samples with developmental disabilities (Breau, Camfield, Symons, et al., 2003). The purpose of the study and the intent of the rating scale (i.e. to measure pain signs) were not revealed to the raters. The scale was 'de-identified' by removing its title and any instructions that related to the assessment of pain signs. Instead, raters were instructed that the scale was being used "to measure the degree of occurrence of a set of nonverbal behaviors." Although the NCCPC is designed to be rated in the context of a recollected painful event (e.g. a fall or an event that lead to an injury), we altered this procedure for this study for several reasons. First, we wanted to minimize the influence of potential staff biases about either pain in persons with mental retardation or persons with self-injury. Second, we were concerned that the reliability and validity of recollected pain events could differ across participants. Third, as this was a group study, we were concerned that the magnitude of potential naturally occurring painrelated events could differ across participants (e.g. one person could have experienced a minor bruise while another could have experienced a major laceration). Thus, the NCCPC items were used to screen for the expressed incidence of a standard set of potential pain signs in a set time period, rather than being used to describe behaviors that occurred in the context of a known event.

\section{Design and analyses}

The NCCPC has not been used previously with adults and its format was modified somewhat (described above) for this sample. Therefore, preliminary item analyses were conducted as a first pass of the data analysis. To identify the most robust and internally consistent scale items to use for analyses, item-level frequency distributions (total sample) and item-total score Pearson correlations were calculated for each scale item. Items that were significantly skewed and/or had insignificant item-total correlations were removed from further analyses. The resulting modified NCCPC total score and the seven subscale scores were then analyzed using (a) an initial ANOVA comparing the groups on NCCPC Total Score and then (b) an overall Group (SIB, Control) by outcome measure (seven subscale scores) MANOVA to compare differences across the seven orthogonal domains measured by the NCCPC. The alpha level was set at .01 for all analyses given the exploratory and multiple comparison nature of the analyses. Correlation analyses were used to examine the association of demographic (age, gender) and clinical (IQ) variables with NCCPC scores for all subjects combined and for each group separately.

\section{Results \\ Item analysis}

All NCCPC scale items (33) were significantly correlated with the total scale score with two exceptions, both in the Activity domain ('Not Moving/Less Active/Quiet', 'Jumping Around/Agitated/Fidgety'). Therefore, these items were dropped from subsequent analyses such that the modified NCCPC Total score was based on 31 items. 


\section{Group comparisons}

As displayed in Figure 1, the SIB Group had a significantly higher modified NCCPC Total score than the Control Group (SIB M $=127.9$ [SD = 33.8] vs. Control $\mathrm{M}=111.3$ [SD = 34.4], $\left.\mathrm{F}_{(1,69)}=4.16, \mathrm{p}=.004\right)$. As displayed in Figure 2, the overall Multivariate Analysis of Variance (MANOVA) effect for the seven NCCPC subscales revealed was significant $\left(\mathrm{F}_{(7,63)}=4.29, \mathrm{p}=.0006\right)$. Follow-up univariate comparisons for each subscale revealed that the SIB Group had significantly higher subscale scores for the Vocal Subscale (SIB M = 10.6 [SD = 4.06] vs. Control $\left.\mathrm{M}=8.0[\mathrm{SD}=4.09] \mathrm{F}_{(1,69)}=7.06, \mathrm{p}=.009\right)$, the Eating/ Sleeping Subscale (SIB M $=6.6[\mathrm{SD}=2.6]$ vs. Control $\mathrm{M}=5.0[\mathrm{SD}=2.9] \mathrm{F}_{(1,69)}=5.14, \mathrm{p}$ $=.026)$, and the Social/Personality Subscale (SIB M $=13.6[\mathrm{SD}=4.29]$ vs. Control $\mathrm{M}=$ $\left.10.0[\mathrm{SD}=3.21] \mathrm{F}_{(1,69)}=16.1, \mathrm{p}=.0005\right)$. There were no significant univariate differences on the Facial Expression, Body/Limbs, or Physiological Subscales.

\section{Correlations}

For the overall group (SIB and Control participants) there were no significant correlations ( $p$ $<.05)$ between NCCPC Total Score and age $(r=0.13)$, gender $(r=.17)$ and IQ $(r=-.02)$. Within group (SIB, Control) correlations for these variables were also non-significant. For the SIB group, there was a modest positive association $(r=0.35, \mathrm{p}<.05)$ between overall pain signs (NCCPC Total Score) and overall severity of SIB (BPI SIB subscale score).

\section{Discussion}

The role of pain in chronic self-injury among individuals with intellectual and developmental disabilities is not well understood. Emerging work in the measurement of pain in nonverbal populations with intellectual impairments has shown that pain and discomfort can be reliably and validly measured (Breau, Camfield, McGrath et al., 2003; Oberlander, Symons, van Dongen, \& Abu-Saad, 2003). In this preliminary study, we used a validated pain scale (NCCPC) designed to measure non-verbal pain behavior to examine differences between matched adults with and without self-injury and developmental disabilities. Two main conclusions can be drawn from the findings. First, the findings are not consistent with a model of pain insensitivity for individuals with self-injury. In this sample, the SIB group had significantly more overall nonverbal pain signs relative to a matched comparison group on a global non-verbal pain measure and item/subscale analyses showed a number of domains in which the SIB group was rated significantly higher (Vocal, Social/Personality, Eating/Sleeping) suggesting the possibility of greater pain expressivity than comparable individuals without SIB. Further, correlation results showed that cases with more severe SIB tended to have elevated overall nonverbal pain signs endorsed and this relationship was not moderated by age, gender, or IQ. Second, this preliminary evidence is consistent with, but not confirmatory of, a model in which pain sensation is intact and its expression amplified among individuals with chronic SIB and intellectual disabilities. One alternative perspective, however, might suggest that the elevated subscale ratings were sensitive to nonspecific mood/behavior problems that would be expected in a group with a chronic behavior disorder. But, the other nonverbal signs corresponding to the NCCPC domains (face, limbs, etc.) were still equal to the Control group which would not be expected or predicted in a pain insensitivity model of SIB. A pain insensitivity model would predict lower scores for the SIB group, which is contrary to the results reported here.

Several features of the study methodology should be pointed out to place the results in the appropriate context. Participants were not selected randomly, limiting the overall external validity of the study. The scale was completed at a single point in time by staff recall (rather than direct observation of any pain episodes). Previous work in this population has shown that caregiver judgments of pain made by direct observation correspond to those of other 
trained observers suggesting that caregivers' judgments can be valid (Breau, et al., 2002). Unlike similar studies, however, and as a way to guard further against bias, we did not link scale completion explicitly to pain events, per se, but rather staff were instructed to record any observed nonverbal behaviors corresponding to the NCCPC items. Thus, the results reflect unbiased judgments about a set of nonverbal behaviors across two well-matched groups. The results are, of course, not specific to pain events, but do show clear betweengroup differences in the incidence of non-verbal pain-related behaviors. For this reason, it is unlikely that each individual's pain experience was well represented. Our purpose, however, was to test for differences at a group level using a validated measure, rather than investigate the specific facets of the individual experience. It is also worth nothing that the likelihood of bias was reduced further because of the matching procedure (i.e., same functional levels) and the fact that individuals in both groups lived in the same environments with the same programs and program staff making it equally likely that the same range of daily events were encountered. Also, rating staff were blind with respect to the specific purpose of the study (i.e., scale information regarding pain was removed), further decreasing the potential impact of observer bias.

Importantly, the data does not address the issue of the causal status of pain in relation to SIB. The scale was not completed based on the occurrence of self-injurious acts or bouts either through recall (i.e., retrospectively) or direct observation (i.e., prospectively). Additional studies with alternative designs focused specifically on SIB are needed. Preliminary work in this area (Oberlander, et al., 2003) suggest that individual differences in pain expression (as measured using facial action coding) can be reliably measured before, during, and after pain experiences or bouts of SIB and this work suggests that SIB subtypes with different 'pain profiles' may exist (e.g., blunted sensation/expression; intact sensation/ blunted expression; intact sensation/expression, etc.) and it may be worth exploring this notion further.

Overall, the results are consistent with an emerging body of work showing that pain and discomfort can be meaningfully measured in populations limited by intellectual, communicative, and motor impairments associated with developmental disabilities (LaChapelle, et al., 1999; Oberlander \& Symons, 2006). The findings are similar to a prior study of pain and self-injury in children with developmental disabilities (Breau, Camfield, Symons, et al., 2003) reporting differences between a pain and no pain comparison group using the same measure. Chronic SIB has been shown to be associated with behavioral (Symons \& Danov, 2005), physiological (Symons, Sutton, \& Bodfish, 2001), and biochemical (Symons, Sutton, Walker, \& Bodfish, 2003) correlates consistent with a model of SIB mediated by pain variables in at least a subset of individuals. The extensive work by Sandman and colleagues (Sandman, 1988; Sandman \& Touchette, 2002) continues to provide confirmatory evidence of endogenous opioid peptide regulation among individuals with chronic SIB. Additional work appears warranted to address more completely the complex relation between pain and self-injury.

\section{Acknowledgments}

This research was supported, in part, by NICHD Grant No. 35682, 40782, 47201 to the University of Minnesota and a McKnight Land-Grant Professorship from the University of Minnesota to Frank Symons. We thank Kelly Sutton, Dawn Parker, and Jamie Clary for assistance with data collection and Alicia Vegell for her editorial assistance. Our sincere thanks to the clients, families, and staff of the J. Iverson Riddle Center for their participation in this study. 


\section{References}

Barrera FJ, Teodoro JM, Selmeci T, Madappuli A. Self-injury, pain, and the endorphin theory. Journal of Developmental and Physical Disabilities. 1994; 6:169-192.

Biersdorff K. Pain insensitivity and indifference: Alternative explanations for some medical catastrophes. Mental Retardation. 1991; 29(6):359-362. [PubMed: 1775077]

Biersdorff K. Incidence of significantly altered pain experience among individuals with developmental disabilities. American Journal on Mental Retardation. 1994; 98(5):619-631. [PubMed: 8192908]

Breau LM, Camfield CS, McGrath PJ, Finley GA. The incidence of pain in children with severe cognitive impairments. Archives of Pediatric and Adolescent Medicine. 2003; 157:1219-1226.

Breau LM, Camfield CS, McGrath PJ, Finley GA. Pain's impact on adaptive functioning. Journal of Intellectual Disability Research. 2007; 51:125-134. [PubMed: 17217476]

Breau LM, Camfield CS, McGrath PJ, Rosmus C, Finley GA. Measuring pain accurately in children with cognitive impairment: Refinement of a caregiver scale. Journal of Pediatrics. 2001; 138:721727. [PubMed: 11343050]

Breau LM, Camfield CS, Symons FJ, Bodfish JW, MacKay A, Finley GA, McGrath PJ. Relation between pain and self-injurious behavior in nonverbal children with severe cognitive impairments. The Journal of Pediatrics. 2003; 142:498-503. [PubMed: 12756380]

Breau L,M, Finley GA, McGrath PJ, Camfield C. Validation of the Non-Communicating Children's Pain Checklist-Postoperative Version. Anesthesiology. 2002; 96:528-535. [PubMed: 11873023]

Breau LM, McGrath PJ, Camfield C, Finley GA. Psychometric properties of the Non-Communicating Children's Pain Checklist-Revised. Pain. 2002; 99:349-357. [PubMed: 12237214]

Breau LM, McGrath PJ, Camfield C, Rosmus C, Finley GA. Preliminary validation of an observational checklist for persons with cognitive impairments and inability to communicate verbally. Developmental Medicine and Child Neurology. 2000; 42:609-616. [PubMed: 11034454]

Defrin R, Pick CG, Peretz C, Carmeli E. A quantitative somatosensory testing of pain threshold in individuals with mental retardation. Pain. 2004; 108:58-66. [PubMed: 15109508]

Grunau, RVE.; Craig, KD. Facial activity as a measure of neonatal pain expression. In: Tyler, DC.; Crane, EJ., editors. Advances in pain research and therapy. Vol. 15. Raven Press; NY: 1990. p. 147-156.

Grunau RVE, Craig KD. Pain expression in neonates: Facial action and cry. Pain. 1987; 28:395-410. [PubMed: 3574966]

Howard RF. Current status of pain management in children. Journal of the American Medical Association. 2003; 290:2464-2469. [PubMed: 14612483]

Iwata BA, Pace GM, Kissel RC, Nau PA, Farber JM. The self-injury trauma (SIT) scale: A method for quantifying surface tissue damage caused by self-injurious behavior. Journal of Applied Behavioral Analysis. 1990; 23:99-110.

Izard CE, Huebner RR, Risser D, McGinnes GC, Dougherty LM. The young infant's ability to produce discrete emotional expressions. Developmental Psychology. 1980; 16:132-140.

LaChapelle DL, Hadjistavropoulos T, Craig KD. Pain measurement in persons with intellectual disabilities. Clinical Journal of Pain. 1999; 15:13-23. [PubMed: 10206563]

McGrath PJ, Rosmus C, Camfield C, Campbell MA, Hennigar AW. Behaviors caregivers use to determine pain in non-verbal, cognitively impaired individuals. Developmental Medicine and Child Neurology. 1998; 40:340-343. [PubMed: 9630262]

Oberlander TF, Symons F, van Dongen K, Abu-Saad HH. Pain in individuals with developmental disabilities: Challenges for the future. Progress in Pain Research and Management. 2003; 24:705723.

Oberlander TF, Gilbert CA, Chambers CT, O’Donnell ME, Craig KD. Biobehavioral responses to acute pain in adolescents with a significant neurologic impairment. The Clinical Journal of Pain. 1999; 15:201-209. [PubMed: 10524473]

Oberlander, TF.; Symons, FJ., editors. Pain in Children \& Adults with Developmental Disabilities. Paul H. Brookes Publishing Co; Baltimore, Maryland: 2006.

Rojahn J, Matson JL, Lott D, Esbensen AJ, Smalls Y. The Behavior Problems Inventory: An instrument for the assessment of self-injury, stereotyped behavior, and aggression/destruction in 
individuals with developmental disabilities. Journal of Autism and Developmental Disorders. 2001; 31:577-588. [PubMed: 11814269]

Rojahn, J.; Schroeder, SR.; Hoch, TA. Self-injurious behavior in intellectual disabilities. Elsevier; NY: 2008.

Sandman CA. Beta-endorphin dysregulation in autistic and self-injurious behavior: A neurodevelopmental hypothesis. Synapse. 1988; 2:193-199. [PubMed: 2463689]

Sandman CA, Spence MA, Smith M. Proopiomelanocortin (POMC) disregulation and response to opiate blockers. Mental Retardation and Developmental Disabilities Research Reviews. 1999; 5:314-321.

Sandman, CA.; Touchette, P. Opioids and the maintenance of self-injurious behavior. In: Schroeder, SR.; Oster-Granite, ML.; Thompson, T., editors. Self-injurious behavior: Gene-brain-behavior relationships. American Psychological Association; Washington, DC: 2002. p. 191-203.

Schroeder SR, Oster-Granite ML, Berkson G, Bodfish JW, Breese GR, Cataldo M, et al. Self-injurious behavior: Gene-brain-behavior relationships. Mental Retardation and Developmental Disabilities Research Reviews. 2001; 7:3-12. [PubMed: 11241877]

Stengel E, Oldham AJ, Ehrenberg ASC. Reactions to pain in various abnormal states. Journal of Mental Science. 1955:52-69. [PubMed: 14368209]

Symons, FJ. Pain and self-injury: Mechanisms and models. In: Schroeder, S.; Thompson, T.; OsterGranite, ML., editors. Self-injurious behavior: Genes, brain, and behavior. American Psychological Association; 2002.

Symons FJ, Danov SE. A prospective clinical analysis of pain behavior and self-injurious behavior. Pain. 2005; 117:473-477. [PubMed: 16154695]

Symons FJ, Sutton KA, Bodfish JW. A preliminary study of altered skin temperature at body sites associated with self-injurious behavior in adults with developmental disabilities. American Journal on Mental Retardation. 2001; 106:336-343. [PubMed: 11414874]

Symons FJ, Sutton KA, Walker C, Bodfish JW. Altered diurnal pattern of salivary substance P in adults with developmental disabilities and chronic self-injury. American Journal on Mental Retardation. 2003; 108:13-18. [PubMed: 12475363] 


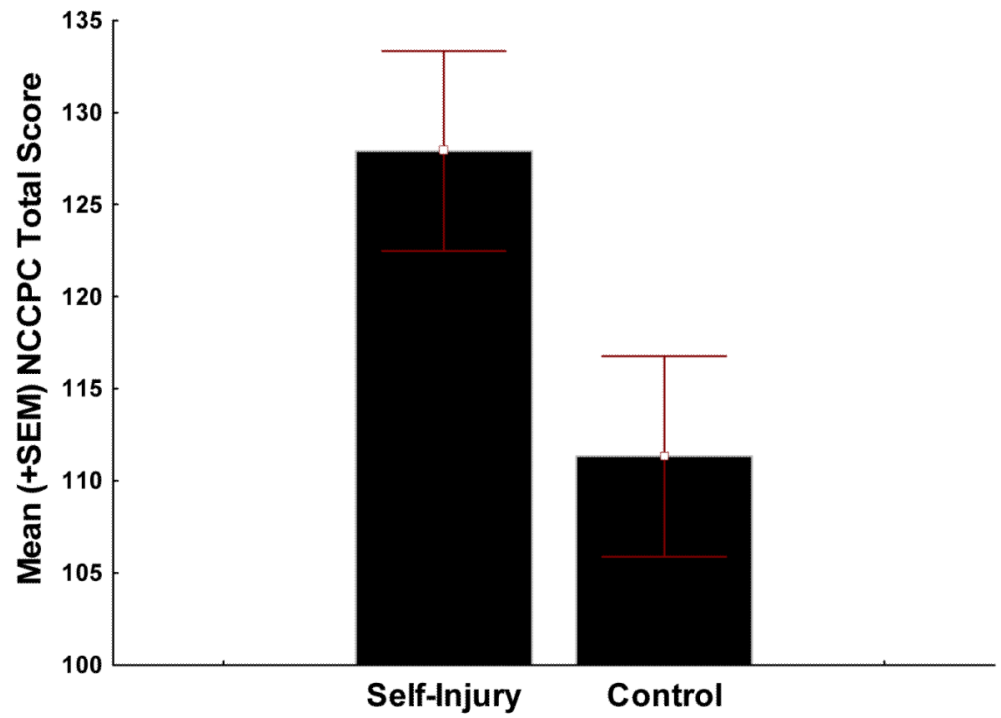

Figure 1.

Mean NCCPC total score between SIB and matched Control group. 


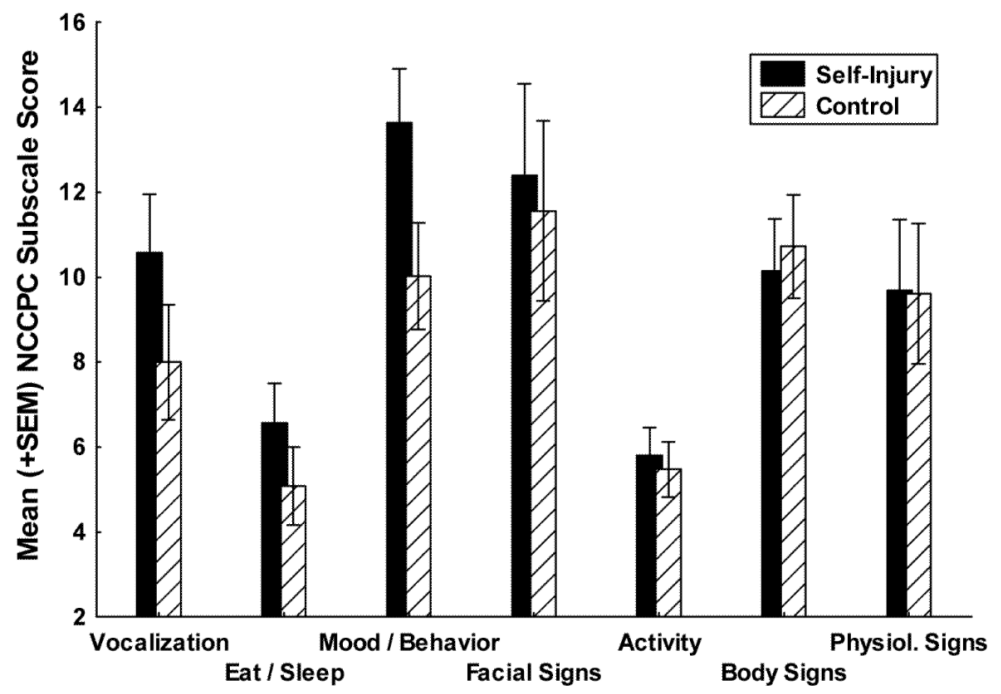

Figure 2.

Mean NCCPC sub-scale scores between SIB and matched Control group. 